\title{
ERRATUM
}

Susanne Jahns

\section{The Holocene history of vegetation and settlement at the coastal site of Lake Voulkaria in Acarnania, western Greece}

Published online: 5 April 2006

(C) Springer-Verlag 2006

\section{Veget Hist Archaeobot (2005) 14:55-66}

In Fig. 4, the names of 6 plants were incorrectly placed. The correct order is: Myrtus, Sarcopoterium-Type, Alnus, Platanus, Juglans, Cistaceae. The corrected part of the diagram is shown below.

The online version of the original article can be found at http://dx.doi.org/10.1007/s00334-004-0053-8.

S. Jahns

Brandenburgisches Landesamt für Denkmalpflege und

Archäologisches Landesmuseum,

Wünsdorfer Platz 4-5,

15838 Wünsdorf, Germany 


\section{Lake Voulkaria}

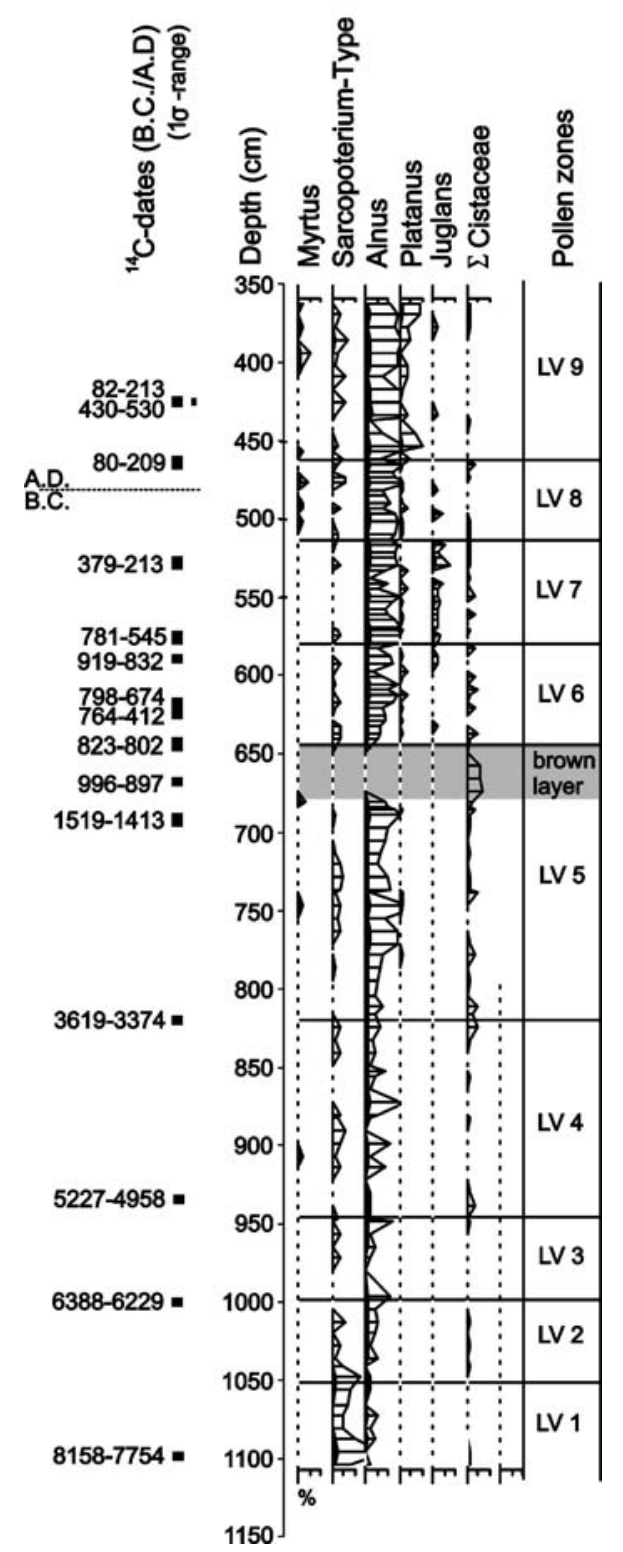

Fig. 4 